\title{
Russian Legal Framework for Digital Tokens
}

\author{
Alekseenko A.P. \\ Vladivostok State University of Economics and Service, \\ Vladivostok, Russia, \\ alekseenko.a.p@gmail.com
}

\begin{abstract}
The adoption of the Federal Law "On Digital Financial Assets", based on the national program "Digital Economy of the Russian Federation", was to take place before December 31, 2018. Despite this, it was adopted in its final version only on July 31,2020 . This regulatory legal act regulates relations related to the use of new digital technologies that can significantly affect the Russian financial market. It was very difficult for the legislator to determine the concept of legal regulation of cryptocurrency and digital tokens, since their complete ban could lead to the movement of public relations data into the shadow economy. Therefore, the legislator has chosen an approach that is based on not prohibiting digital financial assets, but not allowing them to circulate freely. This article examines the Federal Law "On digital financial assets, digital currency and on amendments to certain legislative acts of the Russian Federation" in comparison with previous versions. The author analyzed the provisions of the law on digital tokens. Also, the requirements of the legislation regarding the control over the activities of the network operator in which the tokens are issued were studied. The article concludes that the approach used in Russia is maximally aimed at establishing state control over ICOs and protecting investors. This is achieved through the fact that stringent legal requirements contribute to the occupation of a niche for the provision of digital token operator services by large banks and financial institutions.
\end{abstract}

Keywords-ICO, digital tokens, blockchain, financial assets, cryptocurrency, digital economy

\section{INTRODUCTION}

In January 2021, the Federal Law "On Digital Financial Assets, Digital Currency and on Amendments to Certain Legislative Acts of the Russian Federation" dated July 31, 2020 No. 259-FZ (hereinafter - the Law "On Digital Financial Assets") comes into force in Russia, most of which is dedicated to the issuance of digital tokens (ICO). The work on the law was originally supposed to be completed in 2018. It was assumed that it would regulate not only ICO, but also the procedure for the issuance and circulation of virtual currency, including cryptocurrencies, as well as mining. However, the peculiarities of making investments using digital technologies based on the blockchain system have caused serious disputes in the Russian legal community [1]. In addition, the Central Bank of Russia, the Ministry of Economic Development of the Russian Federation, Rosfinmonitoring [2] and the General Prosecutor's Office expressed radically opposite positions on how to regulate digital financial assets. All this did not contribute to the prompt adoption of the law and led to the fact that the text of the bill was radically changed 3 times.

The first edition of the draft law "On Digital Financial Assets" assumed the regulation of relations related not only to digital financial assets, as stated in the title, but also smart contracts, as well as cryptocurrency mining. In this edition, the legislator also tried to disclose the process of issuing tokens, obliging the issuer to publish an offer and an investment memorandum in order to reduce the risks of investors when investing in such a financial asset as a "token", because these documents indicate data on the issuer and its activities, as well as goals of issue, which allows assessing the risks of investing in this financial asset more objectively. Regarding the turnover of tokens, the legislator provided that they can legally be exchanged for fiat money through the operator of the exchange of digital financial assets, registered in the prescribed manner. In order to protect the rights of investors, there was a limit on the amount by which a person who is not a qualified investor can acquire digital financial assets.

The second version of the bill was significantly different from the first version. It did not mention such concepts as "cryptocurrency", "smart contract", as well as the rules for their regulation. The cryptocurrency was not banned, but it was not allowed either. In fact, the legislator focused only on digital tokens and ICOs. Considerable attention was paid to the accounting of digital tokens, as well as to persons who can keep such records. Unlike the first edition, in the second, digital financial assets are digital rights, i.e. not separate property, but the right to other property, i.e. for certain material objects or services. The second edition of the bill consolidated the full jurisdiction of the Russian law on legal relations arising from the release, accounting and circulation of digital financial assets in accordance with this law, even if there is a foreign person in this legal relationship.

So, the second edition, in comparison with the first, contained more clarifying elements related to ICO. An analysis of the first and second editions of the draft laws suggests that the legislator has decided to tighten control over the circulation and release of digital financial assets, the issuer of which is known. On the one hand, this approach helps protect investors, but on the other hand, it puts the industry in a tight framework. 


\section{PROBLEM STATEMENT}

Difficulties with the adoption of the law "On digital financial assets" showed that the Russian legislator was unable to quickly determine what a cryptocurrency is and how to regulate it. At the same time, in the third edition of the draft, the legislator nevertheless indicated that the virtual currency exists, however, did not explain how it is regulated. Consequently, the procedure for its turnover remained outside the legal regulation. Meanwhile, the fact that cryptocurrency is recognized as an object of civil rights shows that in the near future, one should still expect the adoption of a regulatory legal act that will regulate its use. Perhaps the Central Bank of the Russian Federation will take the initiative in this matter. As for such type of digital financial assets, as tokens, most of the provisions of the law adopted by the State Duma of the Russian Federation are specifically devoted to them, as well as the procedure for their release. In this regard, it becomes relevant to study what risks and benefits they bear for Russian investors and other financial market participants, as well as whether they correspond to the trends in the development of the digital economy. So, before the adoption of the law, Russian scientists expressed various concerns related to tokens. In particular, it was pointed out that the existing legal regimes of objects of civil rights could be replaced by the legal regime of a token [3], it was emphasized that the problem arises of determining the nature of rights to tokens and the means of legal protection of their owners [4]. In addition, certain concerns were expressed about the complexities of taxation [5].

Thus, the adoption of the law "On digital financial assets" makes it necessary to consider the main provisions of the legislation regarding digital financial assets, its impact on the financial market and investors, as well as the field of financial technologies.

\section{PURPOSE OF THE STUDY}

The purpose of this article is to study the Russian approach to the regulation of digital tokens, as well as to identify the provisions of the law "On digital financial assets" that require adjustment. In this regard, the author reviews the Russian legislation on digital tokens, as well as its analysis in a comparative legal vein with the laws of other countries. To do this, the article provides a general description of the adopted law, considers provisions that contain requirements for persons issuing tokens, their accounting.

\section{RESULTS AND DISCUSSION}

The third edition of the draft law "On digital financial assets" was adopted on July 31, 2020. Thanks to this, investors can receive judicial and administrative protection, which they were deprived of before [6]. The adopted version of the draft law is in many respects similar to the second edition of the draft law, however, in contrast to it, it contains fewer prohibitions and restrictions that apply to the circulation of digital tokens. Russian researchers call this option, in contrast to the two previous ones, a compromise [7]. Indeed, many provisions were excluded from its text that impeded the legalization of digital financial assets.

Despite the generally optimistic expectations from this law in terms of ICO regulation, it still has serious flaws. The types of digital financial assets are now on a closed and clear list. They are digital rights, not property, and certify corporate participation rights. So, according to clause 2 of article 1 of the law "On digital financial assets", digital financial assets are nothing more than a certain object that exists in digital form and certifies the corporate rights of their owner. This directly follows from Part 4 of Article 1 of the Law, according to which the issues of issuing digital tokens, if they certify the rights to securities, are subsidiary regulated by Federal Law No. 39-FZ of April 22, 1996 "On the Securities Market", taking into account features provided for by this Federal Law.

From the above, it can be seen that in the law "On digital financial assets" there is no concept of digital tokens, it is actually replaced by the concept of digital financial assets. In addition, the law speaks only of digital financial assets in general, without highlighting the characteristic features of digital tokens and without dividing tokens into types. This does not take into account the actual situation when there are investment and utility tokens, as well as their various subspecies [8]. While investment tokens confirm the right to participate in the company, utility tokens do not possess these qualities and confirm the right to any thing (service) or discount. Both types of tokens are fundamentally different from each other, which means that they require different approaches in regulating their release and circulation. In this regard, the adoption of a single issuance and accounting procedure for all digital tokens casts doubt on the possibility of legal circulation of utility tokens in Russia. This step of the Russian legislator cannot be assessed positively.

Thus, the law "On digital financial assets" does not contain a clear definition of the concept of tokens, does not give their characteristic features. It lists only the rights that can be certified by them. It seems that this state of affairs is a serious flaw in the law and will not contribute to clarity in the field of legal regulation of digital technologies. In this regard, the Russian legislator should amend the law or issue an official clarification that will distinguish utility tokens from others. Now, if we proceed from Article 1 of the Law "On Digital Financial Assets", tokens are understood exclusively as a way to certify the rights of a shareholder.

On the positive side, which is reflected in the final version of the bill, is the rule of law applicable to the issuance of digital tokens. According to clause 5 of article 1 of the law "On digital financial assets", Russian law applies to ICO. This rule applies even if digital tokens are issued with the participation of foreign entities. This requirement cannot be called an excessive restriction and an attempt at extraterritorial application of Russian law. It is in line with international trends regarding ICO. So, in Singapore, which is rightly recognized by researchers as one of the leaders in digitalization [9], based on paragraph 339 of the Securities and Futures Act, in the event that a citizen of Singapore acquires digital tokens, the legislation of Singapore applies extraterritorially to the foreign operator of the platform on the basis of which the placement of such digital tokens is carried out. Consequently, persons carrying out ICO and located outside Singapore must have an appropriate license issued by the competent authority of that state. This approach provides a legal basis to prosecute platform operators regardless of their location and the place where the offense was committed. 
So, the extraterritorial application of Russian law to persons carrying out ICOs in Russia can be assessed positively, however, the competent authorities should issue official clarifications so that foreign organizations that attract funds from Russian investors understand the consequences for them in case of their activities in Russia. In addition, one should decide how the ICO will be regulated if Russian law comes into conflict with foreign law. These issues are extremely important and need to be resolved before the law "On digital financial assets" is fully operational.

Articles 2.3 and 15 of the Law "On Digital Financial Assets" establish the ICO rules. So, only a non-public joint stock company can conduct an ICO. At the same time, only a licensed organization can record the issue of tokens and keep records of transactions performed with them. This requirement is aimed at protecting the rights of investors, as well as maintaining the stability of the stock market.

ICO can only be conducted on the basis of a decision that meets the requirements of Article 3 of the Law "On Digital Financial Assets". So, in particular, the decision to issue digital financial assets must contain information about the issuer of digital tokens; information about the type of rights certified by tokens, the number of tokens, their price, and also the method of their payment; information about the operator of the information system in which digital financial assets are issued, etc. Despite the fact that the list of information that should be reflected in the decision on the issue is quite wide, the Central Bank of Russia has the right to establish additional requirements for the decision to issue digital financial assets. This demonstrates its key role in the issue of by-laws in the field of digital financial assets.

Given the fact that the placement of tokens takes place in a digital environment, the legislator has provided for the requirement that the decision to issue digital financial assets must be signed with an enhanced qualified electronic signature and posted on the website of the issuer and the operator of the information system. This provision of the law allows ensuring that the decision to issue tokens really comes from the person entitled to do so.

An analysis of the provisions of Article 3 of the Law "On Digital Financial Assets" and their comparison with the rules for the issue of shares allows us to say that the Russian law brought the ICO rules as close as possible to how the issue of shares is carried out. It is clear from the law that Russia will treat digital financial assets almost like securities and will regulate tokens similar to shares [10]. This approach is not a Russian invention. Thus, in Singapore, according to the Securities and Futures Act, a token is considered as a digital expression of a security. The experience of applying the legislation on securities to tokens is also available in other countries [11].

In accordance with clause 4 of part 3 of article 13 of the analyzed law, a non-public joint-stock company at its establishment may provide that its shares will be issued in the form of tokens. It is noteworthy that according to article 15 of the Russian law "On digital financial assets" already operating joint stock companies cannot start issuing their shares in the form of tokens. Moreover, if a joint-stock company issues its shares in the form of tokens, then it will lose the right to issue other securities, for example, bonds. This is apparently due to the fact that additional guarantees of the rights of investors are needed, since when working with digital tokens, additional risks arise [12], including those related to cybersecurity. Among the main problems of token circulation, the Central Bank of the Russian Federation sees "the technical danger of abuse in the issuance and circulation of tokens, as well as criminological risks in the event of their exchange for fiat currency" [13]. In addition, there may be problems with accounting for digitally issued shares.

Accounting for digital tokens is the main subject of the "Law on Digital Financial Assets". Eight out of twenty seven articles of the analyzed regulatory legal act are devoted to this issue. Articles 5-9 of the law contain provisions regarding the operator of the information system in which digital financial assets are issued.

According to Article 5 of the analyzed law, the operator of the information system in which the release of digital financial assets (hereinafter referred to as the operator) is carried out may be included in the register of operators of information systems in which the release of digital financial assets is carried out, a legal entity whose personal law is Russian law. The decision to include a particular organization in the register of operators is made by the Central Bank of Russia in accordance with Article 7 of the law in question, as well as the rules of the Central Bank of Russia. It also supervises operators, may establish additional requirements for the content of the rules of the information system in which digital financial assets are issued. The Central Bank of Russia also has the right to exclude operators from the register if they repeatedly violated the provisions of the federal law "On Combating Legalization (Laundering) of Criminally Obtained Incomes and Financing of Terrorism" within one year, and (or) repeatedly within one year violated the regulations of the Central Bank of Russia.

The Law "On Digital Financial Assets" establishes requirements for the activities of the operator of the system where tokens are issued. In addition, the law provides guidance on who can hold leadership positions in the organization that operates the digital token accounting system. So, requirements are imposed on the director's business reputation, education and work experience in managerial positions in the civil service or in a financial organization or in the field of IT technologies. Similar requirements apply to the chief accountant and the head of the internal control service. All this does not contribute to the fact that in the industry the niche of the operator of the system for the release of digital financial assets is occupied by young startups led by innovative entrepreneurs.

In addition, part 8 of article 5 of the law "On digital financial assets" provides a list of persons who cannot hold leadership positions in an organization whose ecosystem is used for ICO. These include, for example, citizens who have an unexpunged or outstanding criminal record, persons convicted of deliberate and (or) fictitious bankruptcy of a legal entity, et.

The operator must notify the Central Bank of the Russian Federation of all appointments to managerial positions (removal from office). The Central Bank of the Russian Federation has the right to demand that one or another manager be replaced if it considers that he does not meet the requirements of the law, including if the manager does not have the necessary business reputation. It is noteworthy that 
these requirements do not apply to banks, depositories and exchanges that operate the operator.

Thus, the Bank of Russia received significant powers in the field of control over organizations that have the infrastructure for ICO. On the one hand, this will provide additional guarantees to investors, but on the other hand, the law may lead to over-regulation. Consequently, in Russia, banks or financial organizations will have an advantage in carrying out activities in the ICO field. Moreover, the law prescribes the operator to have a license of a professional participant in the securities market to carry out activities for maintaining a register, if the operator records the rights to shares of a non-public joint stock company issued in the form of digital financial assets. This approach will maximally contribute to the protection of the stock market, however, at the same time, it will hinder the development of small and medium-sized businesses in the IT field, since the market will give priority to large companies.

Part 3 and Part 13 of Article 5 and Article 6 of the Law "On Digital Financial Assets" also contains provisions that relate to the standards of the operator's activities. They can be divided into organizational, that is, those imposed on the structure of the operator and the presence of internal standards and rules, and operational, imposed on the procedure for carrying out activities.

Organizational requirements include, for example:

- availability of an internal control service and a risk management service;

- rules for making changes to the algorithm (algorithms) of the information system programs;

- $\quad$ rules for issuing digital financial assets;

- standards for information security and operational reliability;

- rules for maintaining the register of token owners.

Operating requirements include:

- the operator's ability to restore access of the owner of digital financial assets to the records of the information system; ensure the uninterrupted functioning of the information system, as well as the integrity and reliability of information about digital financial assets contained in the records of the information system;

- ensuring the correct implementation in the information system of the algorithm (algorithms) for creating, storing and updating information established by the operator of the information system; ensuring the storage of information on transactions with digital financial assets, as well as on participants in such transactions for at least 5 years from the date of the relevant transactions;

- ensuring the actual possibility of exercising rights under equity securities, the possibility of exercising rights under which is certified by digital financial assets.

As you know, one of the most important problems associated with the use of blockchain is the systemic risk that can arise as a result of the unstable operation of the information system [14]. The requirements specified in the law "On digital financial assets" allow ensuring high standards for servicing investors. Therefore, it can be argued that the Russian legislator took into account the risks that arise in connection with the use of blockchain technology. However, it is too early to say how effective the proposed measures will be. In addition, a detailed mechanism for their implementation is required. Therefore, the Central Bank of Russia should develop technical standards to allow regular system testing. This type of testing will identify the operator's ability to respond to the various risks that may arise.

Article 9 of the Law "On Digital Financial Assets" establishes the responsibility of the operator of the information system in which digital financial assets are issued. So, the operator is obliged to compensate the user for losses incurred as a result of the loss of information about digital tokens, a malfunction of the information system, etc.

The indicated bases of operator's liability allow organizing effective protection of the investor. Meanwhile, the legislator needs to pay attention to the fact that in case of damage to the register of token owners, the owner of tokens who does not have proof that they belonged to him will not be able to recover damages, since the only proof of this is the register maintained by the operator. Therefore, it is necessary to ensure the fixation of the registry data not only in the system, but also in another way. In addition, in order for the operator to have an incentive to carry out activities in good faith and make every effort to prevent losses from the customers, it is necessary to provide for the possibility of applying administrative fines or other sanctions to him by the state.

Much attention is paid to the transparency of the register of holders of digital tokens in the law "On digital financial assets".

In order to prevent money laundering and terrorist financing, the information contained in the register of holders of digital tokens must be available to government authorities. Therefore, the operator stores information about the user of the information system (issuer, owner of digital tokens, operator of exchange of digital tokens) in the user register. In this case, the way the user confirms their data is determined by the Central Bank of the Russian Federation. How exactly this operation will be carried out, the Russian regulator has not yet decided.

In addition, the disclosure of information about the owners of digital financial assets and transactions with them can be carried out by the operator at the request of the court, Rosfinmonitoring, the Central Bank of Russia, the Federal Tax Service, the Investigative Committee of Russia, the receiver in bankruptcy of the owner of digital financial assets, as well as other authorized persons. All this ensures absolute access of state bodies to information about the owners of tokens, which fully corresponds to the interests of the state in combating corruption. It is important to note that the information openness of the register of participants in the information system for the bankruptcy administrator in case of bankruptcy of the owner of digital financial assets allows ensuring the protection of the interests of the creditor.

Choosing between the interests of Internet users and the state, Russia followed the path used by many national regulators. Thus, the anonymity of the user is completely 
excluded. Meanwhile, the invention of digital tokens was largely due to anonymity, which made ICO popular [15]. This blurs the line as much as possible between the digital token regime and how stocks are regulated.

\section{V.CONCLUSION}

The adoption in Russia of the law "On digital financial assets" is one of the most important events for the country. With its help, a significant segment of the digital economy will be brought out of the shadows. Despite the desire shown in 2018 to maintain a balance between total control and "anarchy" in legal relations related to digital assets, the legislator nevertheless took the path of tightening control. This was done to protect the rights of investors, but at the same time to protect the interests of the state in the financial sector.

The state, having clearly established control over the circulation of digital financial assets, on the one hand, reduces its risks, and on the other hand, it will be able to provide judicial protection to defrauded investors. Meanwhile, the validity of the methods chosen by Russia to regulate the activities of ICO operators still raises doubts. The adopted rules give more advantages to large investment banks and IT companies. This can negatively affect the development of start-up projects.

\section{Acknowledgments}

The reported study was funded by RFBR, project number 20-011-00454 "Ensuring the rights of investors in the banking and financial sectors in the context of the digitalization of the economy in the Russian Federation and the leading financial centers of East Asia: a comparative legal aspect”.

\section{References}

[1] I. Sarnakov, "Digital Financial Assets: Segments and Prospects of Legal regulation in the BRICS Countries", BRICS LAW JOURNAL, 2019, 6(4), pp. 95-113.

[2] S.S. Emtseva, and N.V. Morozov, "Comparative Analysis of Legal Regulation of ICO in Selected Countries", in Proceedings of III Network AML/CFT Institute International Scientific and Research Conference on
FinTech and RegTech: Possibilities, Threats and Risks of Financial Technologies, 2018, pp. 77-84. DOI: $10.18502 /$ kss.v3i2.1527

[3] A. Savelyev, "Some risks of tokenization and blockchainizaition of private law", Computer Law \& Security Review, 2018, vol. 34(4), pp. 863-869.

[4] V.S. Belykh, and M.O. Bolobonova, "Legal Regulation of Digital Financial Assets in Russia: Controversial Issues of Theory and Practice", Russian Law: theory and practice, 2019, vol. 2, pp. 38-47.

[5] M. Troyanskaya, Y. Tyurina, and E. Ermakova, "Taxation of Digital Financial Assets: International Practices And Comparative Legal Analysis", Talent Development \& Excellence, 2020, vol. 12(2), pp. 1413-1421.

[6] L.N. Khasimova, and E.F. Gumerova, "Digital Rights in Russia: Lega Regulation and Development Prospects", in Proceedings of 2nd International Scientific and Practical Conference on Modern Management Trends and the Digital Economy: from Regional Development to Global Economic Growth, 2020, pp. 1184-1189. DOI: 10.2991/aebmr.k.200502.196

[7] T.E. Rozhdestvenskaya, and A.G. Guznov, "Digital Financial Assets: Problems and Prospects of Legal Regulation", Actual Problems of Russian Law, 2020, vol. 15(6), pp. 43-54. (In Russ.). DOI: https://doi.org/10.17803/1994-1471.2020.115.6.043-054

[8] E. Kirillova, O. Blinkov, T. Zulfugarzade, A. Bocharov, and A Avdalyan, "El estado legal de los tokens y su herencia", Jurídicas CUC, 2020, vol. 16(1), pp. 287-302. DOI: https://doi.org/10.17981/juridcuc.16.1.2020.12.

[9] E. Gorian, (2020). , Smart Technologies and Innovations in Design for Control of Technological Processes and Objects: Economy and Production, in: D. Solovev (Ed.). Chapter in the book: Singapore's Cybersecurity Act 2018: A New Generation Standard for Critical Information Infrastructure Protection, Cham: Springer, 2020. DOI: 10.1007/978-3-030-15577-3_1

[10] A. Alekseenko, "Russian approach to ICO regulation", Revista Genero \& Direito, 2020, vol. 9(4), pp. 874-881.

[11] P. Maume, and M. Fromberger, "Regulations of Initial Coin Offerings: Reconciling US and EU Securities Laws", Chicago Journal of International Law, 2018, vol. 19.2, pp. 548-585.

[12] W.A. Kaal, "Initial Coin Offerings: The Top 25 Jurisdictions and Their Comparative Regulatory Responses", CodeX Stanford Journal of Blockchain Law \& Policy, 2018, vol. 18-07. DOI: http://dx.doi.org/10.2139/ssrn.3117224

[13] G.F. Ruchkina, and D.N. Ermakov, "Analysis of foreign experience in the regulatory framework of distributed ledgers and ico (Initial coin offering) within innovative economy", Humanities \& Social Sciences Reviews, 2019, vol. 7(4), pp. 906-910.

[14] W.J. Magnuson, "Financial Regulation in the Bitcoin Era", Stanford Journal of Law, Business, and Finance, 2018, vol. 23(2)

[15] C. Fisch, "Initial coin offerings (ICOs) to finance new ventures", Journal of Business Venturing, 2019, vol. 34(1), pp. 1-22. 